Research Article

\title{
GENETIC DIVERSITY IN FIBER RELATED TRAITS OF TOSSA JUTE (Corchorus olitorius L.) GERMPLAM
}

\author{
M.T. Islam, B.N. Shompa and J. Rahman* \\ Department of Genetics and Plant Breeding \\ Sher-e-Bangla Agricultural University \\ Dhaka, Bangladesh
}

\begin{abstract}
Genetic diversity of twenty-one genotypes of tossa jute was studied through Mahalanobis $D^{2}$ statistic and principal component analysis for 15 quantitative traits related to yield at the research farm of Sher-e-Bangla Agricultural University, Dhaka, Bangladesh. The genotypes were grouped into four clusters. Cluster III contained the highest number of genotypes (nine), while cluster II had the lowest number of genotypes (three). The inter-cluster distances were higher than intra-cluster distances indicating wider genetic diversity among the genotypes of different clusters. The intra-cluster distances were lower in all the cases reflecting homogeneity of the genotypes within the cluster. The highest intra-cluster distance was noticed for the cluster I and the lowest for cluster IV. The genotypes from cluster I could be selected as parents for hybridization for producing transgressive segregants. The highest inter-cluster distance was found between clusters I and IV followed by clusters I and III and the lowest was between clusters III and IV. Cluster IV recorded the highest mean value for plant height, base diameter, root length, leaf area, fresh weight with and without leaves, dry fiber weight and dry stick weight. In the total divergence, the highest contribution was recorded in plant height $(65.1 \%)$ followed by base diameter (16.6\%). The first two principal components, whose eigen values were greater than one, accounted for $81.7 \%$ of the total variations among the genotypes for fifteen fiber related traits. Considering the magnitude of cluster distance, cluster means for different characters and contribution of characters towards divergence, the genotypes G17, G18 from cluster IV; G1, G2, G5, G10, G16 from cluster I and G4 from cluster III could be selected as promising parents for hybridization program.
\end{abstract}

Keywords: Cluster analysis, $D^{2}$ statistic, Genetic diversity, Principle component analysis, Tossa jute

*Corresponding author: jamilsau@gmail.com

Received: 26.04 .2020

Accepted: 10.07.2020 


\section{INTRODUCTION}

Jute is popularly known as 'Golden fiber' and mainly cultivated for its biodegradable, lignocellulosic bast fiber (Sawarkar et al., 2015a). Globally, jute is familiar as the second most important fiber yielding crops after cotton. India, Bangladesh, China, Nepal, Myanmar and Thailand are the major producers of the total world production of jute, kenaf and allied fibers. Jute occupies a unique position in the national economies of Bangladesh and India in terms of its contributions to employment in industry and agriculture, as also in foreign exchange earnings. In the year of 2018, the total jute production in the world was 3.63 million tons, where India and Bangladesh contributed 3.56 million tons and those were more than $98 \%$ of the global jute production (FAO, 2018). In the year of 2017-18, Bangladesh produced 8895 thousand bales of jute in 1874 thousand acreage of land (BBS, 2018).

The demand of bast fiber of jute is increasing day by day because of its diversified and flourishing needs in different industries e.g., textiles, automobiles, hessians, barlaps, ropes, sacks and agricultural industries (Saha et al., 2017). Generally, there are two popular cultivated jute species in India and Bangladesh, viz., white jute (Corchorus capsularis) and tossa jute (C. olitorius) (Zhang et al., 2015). Tossa jute is comparatively high yielder, producing softer, silkier, stronger and finner fiber as well as expressing more sustainability in the prevailing climatic conditions of the South Asian zone than the white one (Arpita and Kumar, 2016). Due to the high fiber-quality coupled with eco-friendly and biodegradable nature, the demand of the tossa jute fiber is increasing day by day in the western countries (Jatothu et al., 2018) indicating that there is an urgent need to increase the yield levels of jute. The yield levels of the cultivated varieties have plateaued as most of the released varieties were developed from few selected parents.

In a successful plant breeding program, it is an inevitable need to find out the most diverse parents to get high heterotic hybrids or transgressive segregants (Arpita and Kumar, 2016). Analysis of genetic diversity is a basic tool for selection of potential parents in breeding program. Being a self-pollinated crop, jute has very narrow genetic base. Hence, yield improvement of jute remains comparatively challenging through using the subsisting jute varieties or breeding lines (Sawarkar et al., 2015a). Incorporatioin of novel breeding lines having new genetic make-up and diverse genetic bond could overcome the present stagnent and fiber yield sealing in jute breeding program. Thus, assessment of the genetic diversity in the collected jute germplasms is essential for identifying the novel jute genotypes, which could be used as elite parental lines in jute breeding program. Keeping this notion in mind, in the present study we assessed the nature and degree of genetic diversity among twenty-one new accessions of tossa jute for selection of prospective parents to develop transgressive segregants which will be ultimately used for developing modern jute variety. 


\section{MATERIALS AND METHODS}

\section{Plant materials and experimental design}

The plant materials of the study consisted of twenty-one genotypes (5 varieties and 16 accession lines) of tossa jute (Table 1 ).

Table 1. List of twenty-one tossa jute germplasm along with their source

\begin{tabular}{|c|c|c|}
\hline Sl. No. & Variety / Acc. No. & Source / Origin \\
\hline 1. & Var. O-4 (G1) & Bangladesh Jute Research Institute \\
\hline 2. & Var. O-72 (G2) & Bangladesh Jute Research Institute \\
\hline 3. & Var. O-795 (G3) & Bangladesh Jute Research Institute \\
\hline 4. & Var. O-3820 (G4) & Bangladesh Jute Research Institute \\
\hline 5. & Var. O-9897 (G5) & Bangladesh Jute Research Institute \\
\hline 6. & Acc. $4310(\mathrm{G} 6)$ & Bangladesh Jute Research Institute \\
\hline 7. & Acc. 4674 (G7) & Bangladesh Jute Research Institute \\
\hline 8. & Acc. 4785 (G8) & Bangladesh Jute Research Institute \\
\hline 9. & Acc. 4850 (G9) & Bangladesh Jute Research Institute \\
\hline 10. & Acc. 5041 (G10) & Bangladesh Jute Research Institute \\
\hline 11. & Acc. 5085 (G11) & Bangladesh Jute Research Institute \\
\hline 12. & Acc. 5086 (G12) & Bangladesh Jute Research Institute \\
\hline 13. & Acc. 5087 (G13) & Bangladesh Jute Research Institute \\
\hline 14. & Acc. 5088 (G14) & Bangladesh Jute Research Institute \\
\hline 15. & Acc. 5102 (G15) & Bangladesh Jute Research Institute \\
\hline 16. & Acc. 5103 (G16) & Bangladesh Jute Research Institute \\
\hline 17. & Acc. 5120 (G17) & Bangladesh Jute Research Institute \\
\hline 18. & Acc. 5135 (G18) & Bangladesh Jute Research Institute \\
\hline 19. & Acc. 5138 (G19) & Bangladesh Jute Research Institute \\
\hline 20. & Acc. 5155 (G20) & Bangladesh Jute Research Institute \\
\hline 21. & Acc. 5159 (G21) & Bangladesh Jute Research Institute \\
\hline
\end{tabular}

The seeds were collected from the breeding division of Bangladesh Jute Research Institute (BJRI), Dhaka. The field experiemt was conducted in kharif season (March - September) at the research farm of Sher-e-Bangla Agricultural University, Dhaka, Bangladesh. The seeds of each genotype were sown in line during March of kharif - I season $\left(25^{\text {th }}\right.$ March 2017). Randomized complete block design was followed with three replications in the area of $250 \mathrm{~m}^{2}$ research plot and in each replication 3 rows of each genotype were sown maintaining the distance of $5 \mathrm{~cm}$ from plant to plant within each line and $30 \mathrm{~cm}$ from line to line. Before sowing, the seeds were treated with Bavistin @ $2.0 \mathrm{~g} / \mathrm{kg}$ seed. All agronomic practices e.g. weeding, thinning, irrigation, drainage, application of fertilizers and pesticides were followed according to the recommendation of BJRI (Islam and Rahman, 2008). In this field experiment jute was harvested 110-130 days after planting, depending on variety and accessions. Some genotypes were sensitive to short day length, causing 
them to bloom prematurely. These genotypes were harvested within 110 days after planting, just before pods develop.

\section{Observation of morphological parameters}

Data were collected on 15 yield and yield related parameters such as plant height $(\mathrm{m})$, base diameter $(\mathrm{cm})$, middle diameter $(\mathrm{cm})$, top diameter $(\mathrm{cm})$, number of node plant $^{-1}$, number of branch plant ${ }^{-1}$, petiole length $(\mathrm{cm})$, leaf area $\left(\mathrm{cm}^{2}\right)$, root length $(\mathrm{cm})$, root diameter $(\mathrm{cm})$, root weight plant ${ }^{-1}(\mathrm{~g})$, fresh weight with leaves plant ${ }^{-1}(\mathrm{~g})$, fresh weight without leaves plant $^{-1}(\mathrm{~g})$, dry stick weight plant ${ }^{-1}(\mathrm{~g})$ and dry fiber weight plant $^{-1}(\mathrm{~g})$. Five plants of each genotype from each replication were selected at random for recording the data on various parameters.

\section{Stastistical analysis}

Replication means over 3 replications were used for statistical analysis. The genetic diversity among the genotypes was studied following Mahalanobis (1936) generalized distance $\left(\mathrm{D}^{2}\right)$ extended by Rao (1952). Principal Component Analysis (PCA), Principal Coordinate Analysis (PCO), Cluster Analysis (CA) and Canonical Variate Analysis (CVA) were carried out by using GENSTAT 5.13 softwares.

\section{RESULTS AND DISCUSSION}

Genetic diversity provides a rational basis for selection of parents in hybridization programme. The genetic divergence and clustering of the genotypes were studied based on the characters studied and presented in below.

\section{The principal component analysis}

The principal component analysis (PCA) showed eigen values and percent of variation in respect of fifteen component characters of twenty-one genotypes of tossa jute (Table 2).

The principal component analysis (PCA) indicated that only the first two principal components showed eigen values above one and jointly responsible for $81.7 \%$ of the total variation among the genotypes evaluated for fifteen characters or components (Table 2). Jatothu et al. (2018) reported that the first two principal components having the eigen values greater than one accounted for $74 \%$ of total diversity. Denton and Nwangburuka (2012) and Ghosh et al. (2014) also studied the jute genetic diversity and found the similar results. Among the fifteen characters studied here, the principal component I contributed maximum to the value of $65.1 \%$, followed by component II (16.6 \%), component III (5.3\%), and component IV (4.6 $\%)$. Therefore, these component characters could be considered for the selection of elite genotypes in the breeding program. Sawarkar et al. (2015b) studied the genetic divergence among thirty genotypes of tossa jute and reported that fiber yield contributed highest $(43.68 \%)$ towards divergence followed by plant height (20.69 $\%)$, base diameter $(9.66 \%)$ and green weight $(5.28 \%)$. Similar results were also reported by Nayak et al. (2009). 
Table 2. Eigen values and percent variation accounted for by fifteen characters of twenty-one genotypes of tossa jute

\begin{tabular}{cccc}
\hline Principal component axes & $\begin{array}{c}\text { Eigen } \\
\text { values }\end{array}$ & Percent variation & Cumulative \% of variation \\
\hline I & 9.7621 & 65.1 & 65.1 \\
II & 2.4949 & 16.6 & 81.7 \\
III & 0.7967 & 5.3 & 87.0 \\
IV & 0.6878 & 4.6 & 91.6 \\
V & 0.4418 & 3.0 & 94.6 \\
VI & 0.2952 & 2.0 & 96.6 \\
VII & 0.1858 & 1.2 & 97.8 \\
VIII & 0.1257 & 0.8 & 98.6 \\
IX & 0.0797 & 0.5 & 99.1 \\
X & 0.0611 & 0.4 & 99.5 \\
XI & 0.0368 & 0.3 & 99.8 \\
XII & 0.0209 & 0.1 & 99.9 \\
XIII & 0.0099 & 0.1 & 100.0 \\
XIV & 0.001 & 0.0 & 100.0 \\
XV & 0.0004 & 0.0 & 100.0 \\
\hline
\end{tabular}

\section{Clustering of genotypes based upon genetic diversity}

By using Tocher's method (Rao, 1952) the twenty-one genotypes were grouped into clusters and it was found that in total there were four clusters based on the relative magnitude of $\mathrm{D}^{2}$ values (Table 3 and Figure 1).

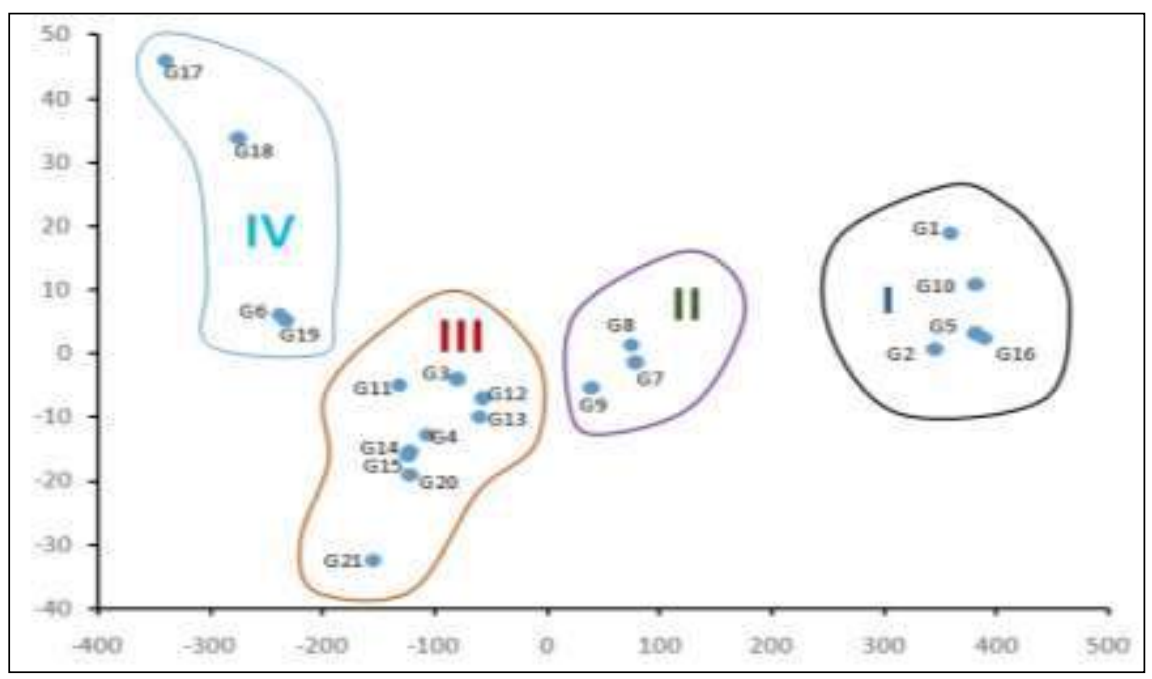

Figure 1. Four clusters of twenty-one genotypes of tossa jute 
Among the four clusters, cluster III contained the highest number of genotypes (nine), while clusters I, IV and II containted five, four and three genotypes, respectively (Table 3). Ghosh and Jethi (2013) studied the genetic diversity of $C$. olitorious and C. capsularis and found four clusters of the genotypes.

Table 3. Distribution of twenty-one genotypes of tossa jute in four clusters

\begin{tabular}{ccc}
\hline Cluster & Number of genotypes & Genotypes \\
\hline I & 5 & G1, G2, G5, G10 and G16 \\
II & 3 & G7, G8 and G9 \\
III & 9 & G3, G4, G11, G12, G13, G14, G15, G20 and G21 \\
IV & 4 & G6, G17, G18 and G19 \\
\hline
\end{tabular}

The inter-cluster distances in all of the cases were higher than the intra-cluster distance indicating wider genetic diversity among the genotypes of different groups. The intra-cluster distance was highest in cluster I (0.740) suggesting higher genetic variation among the genotypes in this cluster and lowest in cluster IV (0.570) suggesting close genetic relationship among the genotypes in cluster IV (Figure 1). Jatothu et al. (2018) also found similar result in tossa jute (C. olitorius) germplasm.

The highest inter-cluster distance was found between cluster I and IV (44.56) followed by cluster I and III (35.67), cluster II and IV (28.1), cluster II and III (19.74), cluster I and II (19.11) and cluster III and IV (8.89) (Figure 2).

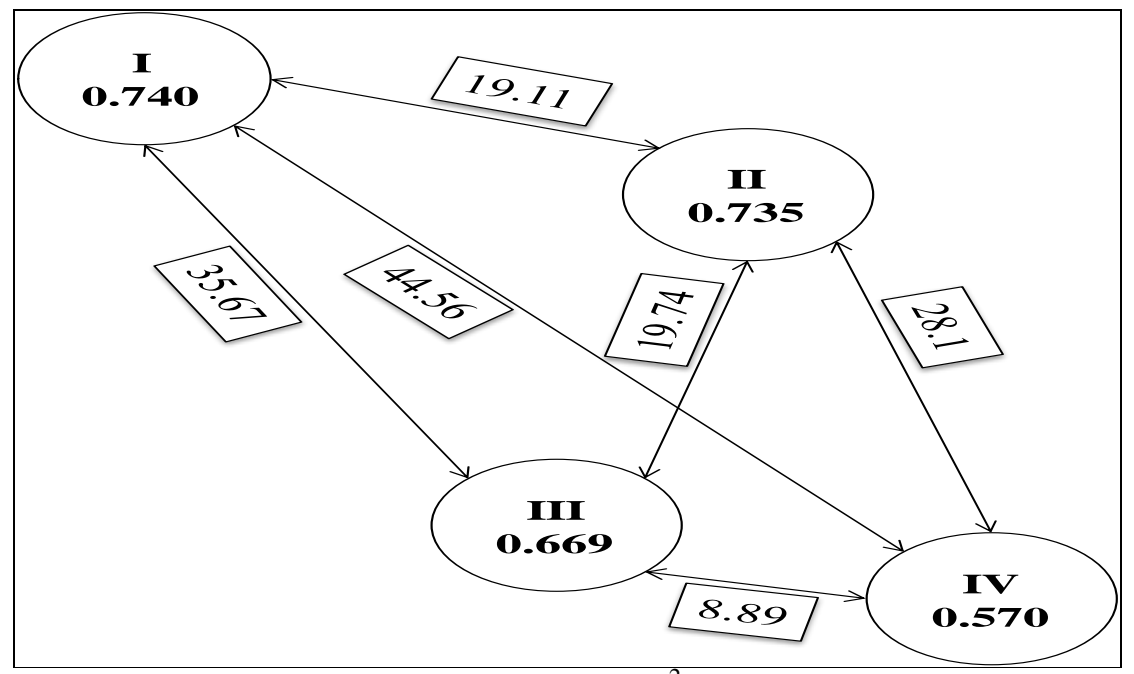

Figure 2. Intra and inter cluster distances $\left(\mathrm{D}^{2}\right)$ for 21 genotypes of tossa jute

Literally, in a hybridization program, it is unexpected to get superior hybrids or segregants from the genotypes belonging to the same cluster. It is believed that the maximum amount of heterosis is obtained in hybrids or segregants involving the 
genotypes belonging to the more divergent origins than the less divergent genotypes (Falconer, 1981). Here, the genotypes belonging to the clusters I and IV had the highest distance, indicating that the genotypes might produce a wider spectrum of segregating populations. Because maximum amount of heterosis is manifested in cross combinations involving the parents belonging to most divergent clusters. So, more emphasis should be given on clusters I and IV to obtain stronger heterosis and broad spectrum of variability in segregatants with new recombination of desired traits. Arpita and Kumar (2016), Akter et al. (2010); Roy et al. (2011) and Jatothu et al. (2018) also reported similar findings while studying genetic diversity in tossa jute germplasm.

\section{Cluster mean analysis}

The results of cluster mean analysis (Table 4) indicated that the genotypes from cluster IV recorded the highest mean performance for plant height $(3.5 \mathrm{~m})$, base diameter $(2.1 \mathrm{~cm})$, middle diameter $(1.5 \mathrm{~cm})$, top diameter $(0.6 \mathrm{~cm})$, petiole length $(3.7 \mathrm{~cm})$, leaf area $(36.6 \mathrm{~cm})$, root length $(15.5 \mathrm{~cm})$, root diameter $(2.3 \mathrm{~cm})$, root weight plant $^{-1}(53.6 \mathrm{~g})$, fresh weight with leaves plant ${ }^{-1}(863.5 \mathrm{~g})$, fresh weight without leaves plant ${ }^{-1}(810.2 \mathrm{~g})$, dry stick weight plant ${ }^{-1}(129.5 \mathrm{~g})$ and dry fiber weight plant $^{-1}$ (43.9 g).

Table 4. Cluster mean of fifteen characters of twenty-one genotypes of tossa jute

\begin{tabular}{|c|c|c|c|c|}
\hline \multirow[t]{2}{*}{ Parameters } & \multicolumn{4}{|c|}{ Cluster } \\
\hline & $\mathrm{I}$ & II & III & IV \\
\hline Plant height (m) & 3.2 & 3.1 & 3.4 & 3.5 \\
\hline Base diameter $(\mathrm{cm})$ & 1.7 & 1.8 & 1.8 & 2.1 \\
\hline Middle diameter (cm) & 1.1 & 1.1 & 1.2 & 1.5 \\
\hline Top diameter $(\mathrm{cm})$ & 0.4 & 0.5 & 0.5 & 0.6 \\
\hline Number of nodes plant ${ }^{-1}$ & 62.6 & 60.1 & 65 & 62.3 \\
\hline Number of branches plant ${ }^{-1}$ & 4.5 & 6.4 & 3.3 & 5.3 \\
\hline Petiole length $(\mathrm{cm})$ & 2.2 & 2.7 & 3.3 & 3.7 \\
\hline Leaf area $(\mathrm{cm})$ & 20.1 & 32.2 & 26.7 & 36.6 \\
\hline Root length $(\mathrm{cm})$ & 13.5 & 14.1 & 14.3 & 15.5 \\
\hline Root diameter $(\mathrm{cm})$ & 1.7 & 1.9 & 2 & 2.3 \\
\hline Root weight plant $^{-1}(\mathrm{~g})$ & 22.2 & 35.8 & 32.7 & 53.6 \\
\hline Fresh weight with leaves plant ${ }^{-1}(\mathrm{~g})$ & 407.7 & 622.5 & 749.9 & 863.5 \\
\hline Fresh weight without leaves plant ${ }^{-1}(\mathrm{~g})$ & 364.6 & 583 & 697.5 & 810.2 \\
\hline Dry stick weight plant $^{-1}(\mathrm{~g})$ & 57.3 & 74.8 & 83 & 129.5 \\
\hline 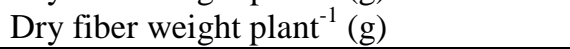 & 19.9 & 24.1 & 30.6 & 43.9 \\
\hline
\end{tabular}

On the other hand, the genotypes from cluster I showed the minimum performance for most of the characters mentioned above. Genotypes in cluster II showed maximum number of branches plant ${ }^{-1}(6.4)$, while genotypes from cluster III showed the minimum performance (3.3). Cluster III showed maximum number of nodes plant $^{-1}(65)$, whereas cluster II showed minimum nodes (60.1). However, the mean 
value of different clusters varied in magnitude that also implies more diversity among the genotypes for all the fifteen characters. Similar findings were also observed by Arpita and Kumar (2016), Alam (2011), Roy et al. (2011), Ghosh et al. (2014) and Jatothu et al. (2018) while studying the genetic diversity in Corchorus spp.

\section{Contribution of characters towards divergence of the genotypes}

Contribution of characters towards divergence was obtained from canonical variate analysis (CVA) and is presented in Table 5. In the first principal component, the number of branches plant ${ }^{-1}$ and in the second principal component, base diameter, middle diameter, top diameter, number of branches plant ${ }^{-1}$, leaf area, root diameter and root weight plant ${ }^{-1}$, fresh weight with and without plant ${ }^{-1}$ leaves, dry stick weight plant $^{-1}$ and dry fiber weight plant ${ }^{-1}$ recorded positive vector values. In both of the vectors (I and II), number of branches plant ${ }^{-1}$ had positive values, revealing the highest contribution towards divergence among the genotypes. On the other hand, in both of the vectors, plant height, number of nodes plant ${ }^{-1}$, petiole length and root length showed negative values, indicating lower contribution towards the divergence. Akter et al. (2010), Denton and Nwangburuka (2012), Jatothu et al. (2018), Hossain et al. (2002) also reported that plant height, base diameter, green weight, stick weight plant $^{-1}$ and number of nodes played principal role towards genetic divergence in the investigations while analyzing the genetic diversity of tossa jute.

Table 5. Relative contributions of the fifteen characters of twenty-one genotypes of tossa jute to the total divergence

\begin{tabular}{|c|c|c|}
\hline Parameters & Vector-1 & Vector-2 \\
\hline Plant height (m) & -0.1751 & -0.4826 \\
\hline Base diameter $(\mathrm{cm})$ & -0.2262 & 0.1775 \\
\hline Middle diameter $(\mathrm{cm})$ & -0.2978 & 0.0014 \\
\hline Top diameter $(\mathrm{cm})$ & -0.2749 & 0.0375 \\
\hline Number of nodes plant ${ }^{-1}$ & -0.0357 & -0.5378 \\
\hline Number of branches plant ${ }^{-1}$ & 0.0289 & 0.5715 \\
\hline Petiole length $(\mathrm{cm})$ & -0.2922 & -0.1682 \\
\hline Leaf area $(\mathrm{cm})$ & -0.2737 & 0.1797 \\
\hline Root length (cm) & -0.2377 & -0.1612 \\
\hline Root diameter (cm) & -0.3062 & 0.0549 \\
\hline Root weight plant ${ }^{-1}(\mathrm{~g})$ & -0.2982 & 0.1175 \\
\hline Fresh weight with leaves plant $^{-1}(\mathrm{~g})$ & -0.2871 & 0.0031 \\
\hline Fresh weight without leaves plant $^{-1}(\mathrm{~g})$ & -0.2852 & 0.0198 \\
\hline Dry stick weight plant $^{-1}(\mathrm{~g})$ & -0.3078 & 0.1085 \\
\hline Dry fiber weight plant $^{-1}(\mathrm{~g})$ & -0.3064 & 0.0517 \\
\hline
\end{tabular}


For crop improvement both the agronomic performance of the genotypes and the characters with the maximum contributions towards divergence should be given emphasis while selecting parental lines (Fatema et al. 2019). Based on the performance of yield and yield related traits together with the magnitude of the genetic divergence of these twenty-one genotypes, G17 and G18 genotypes from cluster IV; G1, G2, G5, G10 and G16 genotypes from cluster I and G4 genotype from cluster III might be selected as potential parental lines for future hybridization programs. Nonetheless, it is worthy to note here that the superiority of a particular genotype in respect of a given character could be diluted by other genotypes that are related and grouped in the same cluster which is inferior for the character in question. Hence, apart from selecting lines from divergent clusters, selection of the parents should also be based on the extent of divergence with respect to the trait of interest.

\section{CONCLUSION}

The investigation on genetic diversity of tossa jute genotypes indicates that there is an appreciable amount of genetic variation among the genotypes. Based on the extent of genetic diversity groups, the tossa jute genotypes were grouped into four diversified clusters which helped to select the genotypes to be used as prospective parents for crossing program. Particularly, the genotypes G17 and G18 from cluster IV; G1, G2, G5, G10 and G16 from cluster I and G4 from cluster III might be selected as these genotypes had the greatest genetic divergence. It may be assumed that upon hybridization their offspring could produce high heterotic combinations and trasgresssive segregants for developing new tossa jute variety.

\section{ACKNOWLEDGMENTS}

The authors would like to thank to Bangladesh Jute Research Institute (BJRI) for providing jute germplasms used in the study. The corresponding author duly acknowledges Ministry of Education (MOE), Banlgdesh for providing the Grant for Advanced Research in Education (GARE) and Sher-e-Bangla Agricultural University for providing research field to conduct the research.

\section{REFERENCES}

Akter, N., Islam, M.M., Yahiya, A.S.M. and Newaz, M.A. (2010). Genetic divergence for fibre and seed characters in tossa jute (Corchorus olitorius L.). Journal of Experimental Biosciences, 1:7-12.

Alam, M.J., Khatun, R., Hossain, M.S., Pervin, N. and Pramanik M.E.A. (2011). Correlation and path analysis in white jute genotypes (Corchorus capsularis L.). International Journal of Sustainable Agrilcutural and Technology, 7:710. 
Arpita, D. and Kumar, D. (2016). Genetic divergence and character association for yield and quality attributing characters in tossa jute (Corchorus olitorius L.). Electronic Journal of Plant Breeding, 7:529-537.

BBS. (2018). Annual Agricultural Statistics 2017-18. Bangladesh Bureau of Statistics, Statistic Division, Ministry of Planning, Government of the People's Republic of Bangladesh.

Denton, O.A. and Nwangburuka, C.C. (2012). Morphologi-cal Diversity among Corchorus olitorius accessions based on single linkage cluster analysis and principal component analysis. Jordan Journal of Biolgical Science, 5:191196.

Falconer, D.S. (1981). Introduction to quantitative genetics $2^{\text {nd }}$ Ed. London: Oliver and Boyd Edinburg. Pp. 164-176.

FAO. (2018). FAOSTAT. Food and Agricultural Organization of the United Nations, Rome, Italy.

Fatema, R., Rahman, J., Shozib, H.B., Nazrul, M.I. and Fatima, K. (2019). Genetic diversity and nutritional components evaluation of Bangladeshi germplasms of kidney bean (Phaseolus vulgaris L.). Journal of Genetic Resources, 5(2): 83-96.

Ghosh, B.K. and Jethi, A. (2013). Growth and instability in world jute production: A disaggregated analysis. International Journal of Electronic Communication and Technology, 4:191-195.

Ghosh, R.K., Wongkaew, A., Sreewongchai, T., Nak-asathien, S. and Phumichai, C. (2014). Assessment of genetic diversity and population structure in jute (Corchorus spp.) using simple sequence repeat (SSR) and amplified fragment length polymorphism (AFLP) markers. Kasetsart Journal of Natural Science, 48:83-94

Hossain, M.B., Haque, S. and Khan, H. (2002). DNA Fingerprinting of jute germplasm by RAPD. Journal of Biochemistry and Molecualr Biology, 35: 414-419.

Islam, M.M. and Rahman, M. (2008). In: Hand book on agricultural technologies of jute, kenaf and mesta crops. Bangladesh Jute Research Institute, Manikmia Avenue, Dhaka-1207, Bangladesh.

Jatothu, J.L., Kumar, A.A., Choudhary, S.B., Sharma, H.K., Maruthi, R.T., Kar, C.S. and Mitra, J. (2018). Genetic diversity analysis in tossa jute (Corchorus olitorius L.) germplasm lines. Journal of Applied and Natural Sciences, 10: 1-3.

Mahalanobi, P.C. (1936) On the generalized distances in statistics. Proceedings of National Academic Sciences of India, 2:49-55.

Nayak, B.K., Baisakh, B. and Bastia, D. (2009). Genetic divergence among genotypes of tossa jute (Corchorus olitorius). Environmental Ecology, 27: 86-88. 
Rao, C.R. (1952). Advanced statistical methods in biometrica research, John Wiley and Sons. New York. USA. Pp. 357-369.

Roy, S.K., Das, B., Kale, V.A. and Haque, S. (2011). Genetic divergence study for yield and quality traits in tossa jute (Corchorus olitorius). Journal of Crops and Weeds, 7(1):130-132.

Saha, D., Rana, R.S., Chakraborty, S., Datta, S., Kumar, A.A., Chakraborty, A.K. and Karmakar, P.G. (2017). Development of a set of SSR markers for genetic polymorphism detection and interspecific hybrid jute breeding. Crop Journal, 5:416-429.

Sawarkar, A., Yumnam, S., Mukherjee, S. and Patil, S.G. (2015a). Genetic divergence within some genotypes of tossa jute (Corchorus olitorius L.). Environmental Ecology, 33:749-752.

Sawarkar, A., Yumnam, S., Patil, S.G. and Mukherjee. S. (2015b). Genetic divergence of tossa jute (Corchorus olitorius L.) for fibre yield and its related component characters under moisture stress condition. Indian Journal of Plant Genetic Resources, 28:263-266.

Zhang, L., Cai, R., Yuan, M., Tao, A., Xu, J., Lin, L., Fang, P. and Qi, J. (2015). Genetic diversity and DNA fingerprinting in jute (Corchorus spp.) based on SSR markers. Crop Journal, 3:416-422. 